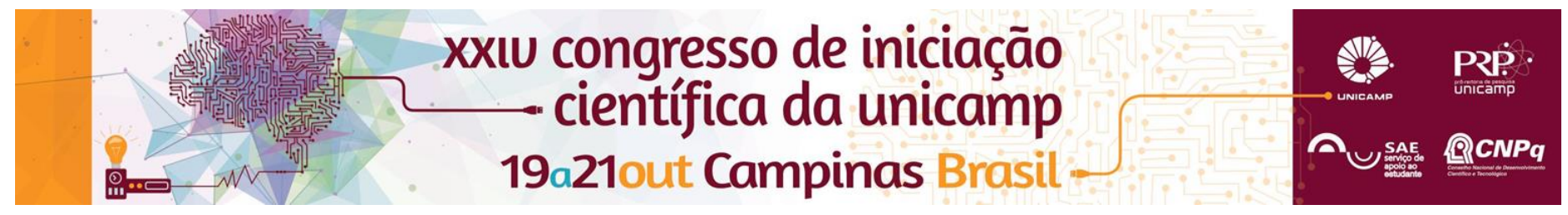

\title{
Efeito de higienizadores nas propriedades brilho, rugosidade, dureza e resistência ao impacto de resina acrílica
}

\author{
Thaís E. Fava*, Moises C. F. Nogueira, Rafael L. X. Consani
}

\begin{abstract}
Resumo
O objetivo foi avaliar o efeito de higienizadores nas propriedades brilho, rugosidade, dureza e resistência ao impacto de resina acrílica. Briho (GU): GA $(76,7)$, GB $(63,7)$ e GC $(63,6)$. Rugosidade $(\mathrm{Ra})$ : GA $(0,91)$, GC $(3,03)$ e $\mathrm{GB}(3,26)$. Dureza: GA $(24,7)$, B $(23,2)$ e C $(23,7)$. Resistência à fratura $\left(\mathrm{kgf} / \mathrm{cm}^{2}\right)$ : GA $(8,5)$, GC $(7,5)$ e GB $(7,3)$. Os higienizadores influenciaram no brilho e na rugosidade, com diferença estatística entre as marcas. Não houve diferença estatística na dureza e resistência ao impacto.
\end{abstract}

\section{Palavras-chave: \\ Resina acrílica, propriedades físicas, limpadores de}

prótese.

\section{Introdução}

O objetivo foi avaliar o efeito de higienizadores nas propriedades brilho, rugosidade, dureza e resistência ao impacto de resina acrílica. Foram confeccionados 60 corpos-de-prova com a resina Clássico e Vipi $(n=10)$ em moldes de gesso obtidos a partir de matrizes retangulares de alumínio incluídas em muflas metálicas, dividos nos grupos: A - controle; B - higienizador Corega Tabs; e C higienizador Kin Oro. Após polimerização dos corpos-deprova em resinas acrílicas térmicamente ativadas no ciclo convencional (água aquecida a $74^{\circ} \mathrm{C}$ por 9 horas), estes foram demuflados após de esfriados à temperatura ambiente e submetidos aos acabamento e polimento convencionais. As propriedades brilho, rugosidade, dureza e resistência ao impacto foram mensuradas após armazenagem dos corpos-de-prova em água a $37^{\circ} \mathrm{C}$ por 24 horas, e após ciclos de imersão por 8 horas diárias para cada higienizador nos grupos B e C (Corega Tabs e Kin Oro, respectivamente), e água destilada no grupo controle, sendo esses procedimentos repetidos por 30 dias. O brilho foi verificado com medidor Multi Gloss 268 (Konica Minolta), com luz incidente de 60 graus, a rugosidade de superfície foi mensurada com rugosímetro (Surfcorder SE 1700; Kosaka), a dureza Knoop em microdurômetro (Shimadzu HMV - 2000), calibrado com carga de $50 \mathrm{~g}$ por 10 segundos com três penetrações (centro e extremidades do corpo-de-prova) e a resistência ao impacto numa máquina Otto Wolpert Werke pelo sistema Charpy, com $40 \mathrm{kpcm}$ de impacto $\left(\mathrm{kgf} / \mathrm{cm}^{2}\right)$.

\section{Resultados e Discussão}

Quanto ao briho, os maiores valores foram obtidos pelo grupo A (76,7 GU), seguido dos grupos B e C $(63,7 \mathrm{GU}$ e 63,6 GU respectivamente). Para rugosidade, os melhores valores também foram obtidos pelo grupo $A(0,91 \mathrm{Ra}-\mu \mathrm{m})$, seguido do grupo C (3,03 Ra- $\mu \mathrm{m})$ e B (3,26 Ra- $\mu \mathrm{m})$. Em relação à dureza, valores semelhantes foram obtidos nos grupos A- 24,7; B- 23,2 e C-23,7. Na resistência à fratura, também foram obtidos valores semelhantes entre os grupos, com grupo A apresentando maior média $(8,5$ $\left.\mathrm{kgf} / \mathrm{cm}^{2}\right)$, seguidos do grupo $C\left(7,5 \mathrm{kgf} / \mathrm{cm}^{2}\right)$ e grupo $B(7,3$ $\mathrm{kgf} / \mathrm{cm}^{2}$ ).

\section{Conclusão}

Os higienizadores influenciaram nas propriedades brilho e rugosidade, com diferença estatística entre grupo controle e demais grupos para todas as marcas comerciais $(p<0,001)$. Não houve diferença estatística com relação à dureza e resistência ao impacto.

\section{Agradecimentos}

Os autores agradecem o apoio do CNPq/SAE/UNICAMP para o desenvolvimento da pesquisa na Faculdade de Odontologia de Piracicaba da Universidade Estadual de Campinas, SP, Brasil.

Anusavice KJ. Phillips Materiais Dentários. 11. ed., Rio de Janeiro; Elsevier: 2013.

Bollen CM, Lambrechts P, Quirynen M. Comparison of surface roughness of oral hard materials to the treshold surface roughness for bacterial plaque retention: a review of the literature. Dent Mater 1997; 13: 258-269.

Cakan U, Kara O, Kara HB. Effects of various denture cleansers on surface roughness of hard permanent reline resins. Dent Mater J. 2015 Apr 1;34(2):246 51. doi: 10.4012/dmj.2014-194. Epub 2015 Feb 25

Felipucci DN, Davi LR, Paranhos HF, Bezzon OL, Silva RF, Pagnano VO. Effect of different cleansers on the surface removable partial denture. Braz Dent J 2011 22: 392-397.

Harman IM. Effects of time and temperature on polymerization of a methacrylate resin denture base. J Am dent Assoc 1949; 38 (2): 188-203.

Jackson AD, Grisius RJ, Fenster RK, Lang BR. The dimensional accuracy of two denture bases processing methods. Int J Prosthodont 1989; 2 (5): 421-8.

Jung M, Eichelberger K, Klimek J. Surface geometry of four nanofiler and one hybrid composite after one-step and multiple-step polishing. Oper Dent 2007 32(4): 347-55.

Khan Z, Von Fraunhofer JA, Razavi R. The staining characteristics, transverse strength, and microhardness of a visible light-cured denture base material. J Prosthet Dent 1987; 57(3): 384-6.

Paranhos HF, Silva-Lovato CH, Souza RF, Cruz PC, Freitas KM, Peracini A. Effects of mechanical and chemical methods on denture biofilm accumulation. J Oral Rehabil 2007; 34: 606-612

Peracini A, Davi LR, de Queiroz Ribeiro N, de Souza RF, Lovato da Silva CH, de Freitas Oliveira Paranhos H. Effect of denture cleansers on physical properties of heat-polymerized acrylic resin. J Prosthodont Res 2010; 54: 78-83.

Polychronakis NC, Polyzois GL, Lagouvardos PE, Papadopoulos TD.Effects of cleansing methods on 3-D surface roughness, gloss and color of a polyamide denture base material. Acta Odontol Scand. 2014 Nov 4:1-11.

Rodrigues Garcia RC, Joane Augusto de S Jr, Rached RN, Del Bel Cury AA. Effect of denture cleansers on the surface roughness and hardness of a microwave-cured acrylic resin and dental alloys. J Prosthodont 2004; 13: 173178.

Skinner EW. Acrylic resins: an appraisal of their use in dentistry. J Am Dent Assoc 1949; 39 (3): 261-8. 